\title{
Universities as marketplaces
}

[Book Review] William M. Bowen, Michael Schwartz and Lisa Camp (eds) (2014) End of Academic Freedom: The Coming Obliteration of the Core Purpose of the University. Information Age Publishing, Charlotte, NC, ISBN: 978-1-62396-658-4, 212 pp, \$45.99 (paperback)

Emmeche, Claus

Published in:

Science \& Education

DOI:

10.1007/s11191-015-9759-5

Publication date:

2015

Document version

Peer reviewed version

Document license:

Unspecified

Citation for published version (APA):

Emmeche, C. (2015). Universities as marketplaces: [Book Review] William M. Bowen, Michael Schwartz and Lisa Camp (eds) (2014) End of Academic Freedom: The Coming Obliteration of the Core Purpose of the

University. Information Age Publishing, Charlotte, NC, ISBN: 978-1-62396-658-4, 212 pp, $\$ 45.99$ (paperback).

Science \& Education, 24(7), 1047-1054. https://doi.org/10.1007/s11191-015-9759-5 
Claus Emmeche (2015): “Universities as marketplaces", Science \& Education 24(7)1047-1054. [review of: William M. Bowen, Michael Schwartz and Lisa Camp, eds. (2014): End of Academic Freedom: The Coming Obliteration of the Core Purpose of the University. Information Age Publishing, Charlotte, NC] DOI 10.1007/s11191-015-9759-5.

This version below is the author's own, before the final layout and proofs.

\title{
Universities as marketplaces
}

\author{
William M. Bowen, Michael Schwartz and Lisa Camp (2014) End of Academic Freedom. \\ The Coming Obliteration of the Core Purpose of the University. Information Age \\ Publishing, Charlotte, North Carolina. ISBN: 978-1-62396-658-4, 212 pages, price: \\ $\$ 45.99$ (paperback)
}

Reviewed by: Claus Emmeche, Center for the Philosophy of Nature and Science Studies, Department of Science Education, University of Copenhagen, Copenhagen, Denmark. Email: cemmeche@ind.ku.dk

\section{Introduction}

As the long subtitle indicates, the book under review is concerned with the widespread challenges to universities in terms of increased political pressures to be governed according to a narrow set of measures of output efficiency and job creation effects, at the expense of their core purpose as institutions of higher education and research. The authors of the book are university professors with a background in US social science and professional experiences as university leaders and administrators, deans, presidents, and fundraising consultants. Two of them have previously published on matters of university politics (Bowen $\&$ Schwartz 2005; in a note they state that of the book's nine chapters, chapter 5 through 9 draw heavily upon this earlier work).

The aim of analyzing the core purpose of contemporary universities is a highly welcome one, considering that institutions of higher education today are rapidly changing and highly exposed and susceptive to shifting political regimes of governance. These pressures interfere with the institutional autonomy they have achieved to varying degrees, depending upon the different political and historical contingencies and the social contexts they are situated in. The situation calls for differentiated and comparative analytical approaches to meet the promise of the title of the book, talking about 'the core' purpose and 'the coming' of certain threats against academic freedom.

The authors present their book as based upon the assumption that the core purpose of universities is to create, preserve, transmit, validate, and find new applications for knowledge. They argue that university governance processes should take ideas and discourse about ideas far more seriously than they are often taken within many of today's universities. Universities should consciously recognize and conserve, as the authors phrase it, the entire range of available ideas, rather than primarily focus upon economy and efficiency as a dominating perspective because the later tends to curtail academic freedom. The book presents arguments and critical reflections about the control and monitoring of what they call "the marketplace of ideas", a metaphor they find attractive as "the competition of ideas leads more readily to progress than any other path" (p.39). In the beginning chapters of their book, Bowen, Schwartz and Camp are preoccupied with describing the history of US higher education; some of the organizational structures and constraints upon the flow of information 
within universities; the role of language and group-based situated understanding in university governance; and the relationships between administrators, faculty members and students, always emphasizing the heterogeneous purposes of teaching, research and development.

Among the impediments to achieving the core purpose of universities, the authors identify and discuss five major such 'idea inhibitors' or 'vetting systems', as they also call them (alluring to the political sense of vetting as a strictly biased selection process). These five impediments are authoritarianism, corporatism, illiberalism, supernaturalism, and political correctness. The authors try to elucidate how these phenomena inhibit achievements at various levels, and want to show how to respond to such threats. They are prescribing relatively autonomous universities to counter unhealthy tendencies. Such universities are characterized by openness, transparency, dissent, and the maintenance of balance between conflicting perspectives, values, and interests. Although one may find the singling out of some of the threats to academic freedom a bit surprising, their US perspective may explain this and the authors clarify in some detail in their selection of perils and give reasoned arguments connected to each threat, at least on a general level.

The fact that threats to academic freedom in many respects are global makes it a bit disappointing that the authors, writing from a North American background, do not investigate how these trends are manifested globally (cf. Frank and Gabler 2006, de Brary 2010) or try to compare and distinguish global trends from local peculiarities. This means that some of the threats to academic freedom they describe, such as corporatism, can be recognized widely across major regions, while others, such as the threat of religious influence ('supernaturalism') or of 'political correctness' may seem more local. They discuss and criticize political correctness both from the right and in particular from the left, and the concomitant tendency to "flee from serious, open, political debate" at campus, but they give no real analysis of the very notion of political correctness, or indicate that it is in itself an inherently contested concept. A discussion of the genealogy of this phenomenon or of specific cases would have been instructive. This lack gives the book a certain taint of parochialism and limits its use or outreach. Adding to this impression is the way the authors often implicitly refer to phenomena that may have been highly debated in their local communities but without giving the reader any hint or references to the cases discussed. An example is their mentioning of a certain "conspiracy theory of ignorance" (p. 70ff) that they neither explain nor provide any references to, leaving it to the reader to search the internet and find that it might refer to writer and newspaper reporter Martin L. Gross' institutional critique of the presumed low standards of US basic education and of the 'education establishment' (Gross 1999). A more active editorial process at Information Age Publishing could have improved the book in such cases.

This is not to denigrate the mentioning of local debates or specific examples, if properly contextualized and documented. In fact, at long passages, such illustrations could have enriched the rhetorical style of a text that at some points is experienced as a thinly abstract lingo of complex systems thinking, stating generalities and abstaining from concretizing the tendencies discussed. No doubt the authors draw on their large pool of academic and managerial experience, and perhaps they take care not to damage the reputation of colleagues and institutions they have interacted with, but a very generalized discourse is a tiring read and it often feels repetitive. In this sense, the book stands in sharp contrast to the seminal piece on academic freedom in the US by Matthew Finkin and Robert C. Post (2009) that, apart from offering a clear conceptual analysis of the very notion of academic freedom, its elements (freedom of research and publication, freedom of teaching, freedom of intramural expression and of extramural expression) and the legal background for these elements, is well illustrated with historical controversies, precedents and cases. 


\section{Carving up the threats against academic freedom}

The authors of The End of Academic Freedom declare that it is written "in the perspective of critical university studies" (back cover) but they do not present any conspicuous efforts to relate the book scholarly to that tradition, draw from its sources, or even specify how their contribution stands out from that very heterogeneous field. Compared to other contributions to critical university studies (e.g., Kirp 2003; Geiger 2004; Slaughter and Rhoades 2004; Bousquet 2008; Karran 2009; Radder 2010; Nixon 2011), their book has more the character of a sketchily assembled manifesto. To illustrate this, let us compare their diagnostics of threats divided into the five categories with other contributions to the field, such as the widely acclaimed report by English professor and president of the American Association of University Professors between 2006 and 2012, Cary Nelson, i.e., his 2010 book (see Table 1). Nelson's threat taxonomy, though overlapping with that of the authors' of The End of Academic Freedom, is more fine-grained, less idealist, and duly sensitive to the importance of tenure as a supportive structure for academic freedom.

Table 1. Comparison of threats to academic freedom as categorized by the book under review (the five threats on the right) and by Nelson 2010 (the sixteen threats below). Descriptions of the same or similar phenomena by the categories are marked by an $x$. If there is uncertainty about sameness or similarity, this is marked by an $(x)$. See text for explanation.

\begin{tabular}{|c|c|c|c|c|c|}
\hline & 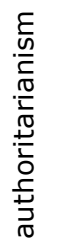 & $\begin{array}{l}\frac{E}{5} \\
\frac{0}{0} \\
\frac{0}{0} \\
\frac{0}{0} \\
\frac{0}{0} \\
0\end{array}$ & $\begin{array}{l}\frac{\varepsilon}{\frac{\varepsilon}{\bar{N}}} \\
\frac{\sqrt{0}}{0} \\
\stackrel{0}{\equiv}\end{array}$ & 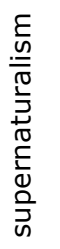 & 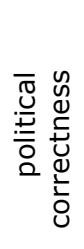 \\
\hline 1. Instrumentalization & & $\mathrm{x}$ & & & \\
\hline \multicolumn{6}{|l|}{ 2. Contingency } \\
\hline 3. Authoritarian administraton & $\mathrm{x}$ & & & & \\
\hline 4. Abuses of the national security state & & & $(\mathrm{x})$ & & \\
\hline \multicolumn{6}{|l|}{$\begin{array}{l}\text { 5. Administration restrictions on the use of } \\
\text { communication technology }\end{array}$} \\
\hline 6. Unwarrented research oversight & $\mathrm{X}$ & & & & \\
\hline 7. Neoliberal assaults on academic disciplines & & $\mathrm{X}$ & & & \\
\hline 8. Managerial ideology & $\mathrm{x}$ & $\mathrm{X}$ & & & \\
\hline 9. Circumvention of shared governance & $\mathrm{x}$ & $\mathrm{x}$ & & & \\
\hline \multicolumn{6}{|l|}{ 10. Globalization } \\
\hline \multicolumn{6}{|l|}{ 11. Opposition to human rights } \\
\hline \multicolumn{6}{|l|}{ 12. Inadequate grievance procedures } \\
\hline 13. Religious intolerance & & & & $\mathrm{x}$ & \\
\hline 14. Political intolerance & & & $(\mathrm{x})$ & & $\mathrm{X}$ \\
\hline 15. Legal threats & & & & & \\
\hline 16. Claims of financial crisis & & & & & \\
\hline
\end{tabular}

The authors of The End of Academic Freedom define authoritarianism in general terms as something that recognizes only authority that resides in an individual person, providing no room for dissent, or careful systematic consideration of various competing ideas or 
perspectives (p.120). In the academy, individual carriers of authoritarian ideas "potentially include politicians, wealthy trustees and donors, accrediting agencies, senior university administrators, and faculty members alike" (p.121). Two ways for authoritarianism to take form, according to the authors, is to limit academic freedom or restrict resources in specific areas of development. As an example they mention the post 9/11 concerns for national security that led a group called Campus Watch emerge to monitor and 'review and critique' the work of key faculty members of Middle East Studies allegedly to counter errors and biases in their scholarship (p.122). Other examples include a company offering to construct a building for a certain program on campus, but in return the university had to guarantee priority to research results that might give this company a substantial advantage. As one can see, the category of authoritarianism is fairly broad, and overlapping with several of Nelson's more narrow categories. It should be said that Nelson's list is seen by himself as provisional and enumerating threats that overlap and interact. He says that a decade ago he might "have collapsed several of these entries under the single heading of 'corporatization', but the evolving culture of higher education now requires further differentiation of the forces shaping our present and our future. They are no longer narrowly economic. If there is a single heading under which we can list the forces operating on higher education, it may well be "neoliberalism"' (Nelson 2010, p. 60).

Most of the threats broadly categorized by the authors are also covered by Nelson's list, except perhaps 'illiberalism', to be discussed below. But Nelson's list reveals some dangers to academic freedom not dealt with in any depth by Bowen, Schwartz and Camp (cf. Table 1). This includes, for instance, the problems of contingency, i.e., non-tenured contingent teachers often teaching more than half of the teaching loads but with a much more precarious position to benefit from their rights to free intramural and extramural speech. Another problem are restrictions on the use of email and other communication technology (such as breaches of letter privacy). Nelson also considers globalization, when for instance universities seek to market their products in other countries and may be tempted to abandon the standards that protect academic freedom in their home institutions. Opposition to human rights, including rights for employee groups to bargain collectively, is also a serious factor affecting academic freedom, which - like lack of grievance procedures, legal threats and claims of financial crisis as an excuse to re-organize or cut-down faculty - call for more specific analyses, as they do not fit easily into the five categories given by the authors.

'Illiberalism' or 'anti-liberalism' is defined not as being against liberalism in the US political sense, but as against what the authors call the 'liberal mindset' embedded in the notion of liberal education. In their idealist vein, the authors state that this mindset "recognizes, appreciates, and respects the systematic unity of reason", giving great weight to the aim of striving for "coherence, uniformity, consistency, generality, and harmony of thought in all state of affairs" (p. 138). In order to understand both the philosophical-political stance of the authors and what I see as a failure to posit themselves adequately within such traditions (as they stick to a standard liberal-conservative dichotomy), it is beneficial to pay attention to the continuation of their remark: The 'liberalism' (that they need as their contrast to define illiberalism as one more threat to academic freedom) "seeks to use the best possible knowledge to inform decision processes and, insofar as possible, to assume views and build and maintain institutions that are optimally conducive for the use of reason and rationality in the resolution of conflict throughout society." (p.138).

Although this draws an outline of a sympathetic stance, and a viewpoint that fits well with an adherence to the pragmatism of Charles Sanders Peirce (and indeed they hurry to enroll Peirce in 'a liberal epistemological position', p. 140), the insistency upon a uniformity of thought in all state of affairs is also something of a heavy metaphysical proclamation that is problematic from the point of view of post-positivist philosophy of science, having 
emphasized that research comes in many forms and that a plurality of styles of reasoning or styles of inquiry is at work across the disciplines (e.g., Hacking 2002). At least, room should be made for dissenters that prefer to adhere to a more pluralist 'disunity of science' metaphysics that does not aim at a grand synthetic ontology or metaphysics of science equally valid for all fields across the natural and social sciences and the humanities. Just like the importance of freedom of religion in society at large, there should also be a similar acknowledgement of a 'freedom of metaphysics' within science and scholarship in general. This allows researchers to work together on research projects within or across disciplines without first having to reach consensus on their ultimate metaphysical convictions, just like citizens of all religious convictions collaborate within the institutions of an open society.

But what is more important in the quoted statement is an awareness of a central value of universities for society at large because of their impact as institution-building and institutionmaintaining entities. The authors try to hide their allegiances to some place on a fragile balance between liberal and conservative sentiments in the US political sense. However, they inadvertently slide back to this political sense of 'liberal' when they argue for policies that would advance the causes of a limited government, inspired by Hayek (p. 139). Their cause could have been better expressed and theoretically embedded had they articulated it by the conceptual vocabulary of the republican tradition of political thought with its focus on strong institutions as a precondition for a well-functioning democracy (see Fukuyama 2004 and later works).

In accusing academics and students for 'illiberalism' one of their more specific targets seems to be the epistemic relativism in postmodernist thinking, typical of the 1990s, and in general what the authors sense as "an intellectual atmosphere in which all alleged facts and reason - the underpinnings of all knowledge - were portrayed as being political derivatives of those in power, or those seeking power" (p. 144). Radical epistemic relativism is indeed deeply flawed and self-defeating, but also there seems to be a subtle slide from a critique of a certain debate climate or intellectual atmosphere lacking tolerance and open-mindedness to a critique of a philosophical flaw that is not fully spelled out. And one may wonder how well their own wish to expel 'illiberalism' sits with their mission statement that the university should aim at conserving "the entire range of available ideas", "the complete range of thinkable thoughts" (p.113). Even though we might see the university as a "storehouse of ideas" (ibid.), this metaphor misrepresents the dynamics of critical evaluation and constant reinterpretation of knowledge.

\section{The marketplace of ideas}

The authors are very skeptical about neoliberal enforcements like outcome indicators reflecting enrollments, graduation rates, research productivity, etc., and they rightly claim that the choice of which productivity indicators to use is an inherently political one (p. 29). Yet, there is no detailed analysis of new public management or other neoliberal installations of governance. They note that decisions that affect productivity of universities "are not simple matters that boil down to rationally choosing what works from what does not work" (p.30), and they see these as being about control and balance between value tradeoffs in continually challenging decision situations. But the alternative they offer is not what one might have expected, say, in the form of a republican vision of universities as institutions providing for not only science and technology for the market, but also an ideational infrastructure for a modern state and its civic society with strong democratic institutions of health, environment, education, culture, political communication and security. 
The alternative they offer seems to be just another economic metaphor for the university, not that of a production unit, but 'a free marketplace of ideas' (pp. 31, 39, 144). They think that to achieve the best possible performance within university communities, the designs for governance and control structures determining the flow of information should be predicated upon the premise that a free marketplace of ideas directly promotes the advancement of knowledge and indirectly promotes social and economic progress as well. In a note they refer to philosopher and Hayek's disciple William Warren Bartley, III, for an analysis of this metaphor (Bartley 1999) that can be tracked to several sources, among them most famously the Hungarian-British polymath Michael Polanyi whom they don't mention. Polanyi debated research policy and how to legitimate basic research with the socialist and scientist John D. Bernal in the 1960s (Mirowski 1997; Fischer and Mandell 2009). Already at that time Polanyi's vision of an autonomous 'republic of science', which would be publicly funded, but in which the scientific community itself would set priorities, was seen by many as politically naïve, considering the increasing expenses on research and the close ties between basic and applied research. Bowen, Schwartz and Camp basically repeat that vision, but fail to connect it to a socially sensitive analysis of the edifying character of modern universities, not just in an ideational sense, but in their social functions as having institution-building and maintaining capacities, as emphasized by Fukuyama (2004). Neoliberal theory as well as metaphors about the marketplace of ideas, even when supplied with complex systems thinking and evolutionary epistemology, fail to comprehend the central role for universities as places cultivating expert cultures and providing professional resources and a cognitive infrastructure for the democratic societies.

Bowen, Schwartz and Camp hesitate to formulate what the core purpose of the university should be: Because of the complexity of today's university governance, no single mind can comprehend all dimensions of the decisions that have to be taken, or their effects on the entire university, so they consider questionable the premise that a university ought to have any single or dominant goal. They think that it is the absence of any such purposes or goals that best allows students and individual faculty members the freedom to exchange their ideas and pursue their diverse self-interested goals and purposes, and so to contribute to knowledge formation most effectively. Thus, insofar as universities are markets in which students and faculty members freely supply and demand ideas, it is neither feasible nor desirable to attempt to control or shape them to conform to a single notion of a higher purpose. Yet, later on they link the core purpose to the preservation of a high variety of ideas (pp. 51, 113ff, 166).

Their own use of the ideas of evolutionary epistemology in the Hayek mode is hopefully better explained in their earlier work (Bowen and Schwartz 2005); in the book under review, the reader has to guess the structure of their underlying model. They seem to imply a cybernetic approach to the selection and retention of epistemically useful ideas, but this is not well developed in the text, and one gets the suspicion that natural selection is not the best explanatory scheme for understanding the creation and evaluation of new concepts, models or theories, or their further development. The authors are concerned about undue narrowing of the variety of ideas, but they often talk simplistically about ideas like neatly delimited items that appear and disappear as if they were genetic mutations. For instance, we learn that in "contrast to Darwin's big idea of particulate inheritance, which so far seems to have withstood the test of scrutiny, Marx's big idea of communism seems to have largely come and gone" (p. 116). One cringes at reading such statements, considering the complexity of Darwin's or Marx's work and its reception; Darwin's thoughts about inheritance were not particularly endurable, and the communism that have come and gone cannot be ascribed to Marx without committing historical reductionism. 
This has of course nothing to do with the overall value of a welcome manifesto to combat the threats to academic freedom, but getting too many details wrong not only detracts from scholarly value, but it also bedevils the good intentions. The book begins with an epigraph quoting The Limits of State Action by Wilhelm von Humboldt (his name comes with a typo) on the "The true end of Man, or that which is prescribed by the eternal and immutable dictates of reason" and ends with the mini-biographies of the authors. It lacks an index.

\section{References}

Bartley WW III (1990) Unfathomed knowledge, unmeasured wealth: on universities and the wealth of nations. Open Court, LaSalle, IL.

de Bary B (2010) Universities in translation: the mental labor of globalization. Hong Kong University Press, Hong Kong.

Bousquet M (2008) How the university works. New York University Press, New York.

Bowen WM and Schwartz M (2005) The chief purpose of universities: academic discourse and the diversity of ideas. The Edwin Mellen Press, Lewiston, NY.

Finkin MW and Post RC (2009) Principles of American academic freedom. Yale University Press, New Haven \& London.

Fischer F and Mandell A (2009) Michael Polanyi's republic of science: the tacit dimension. Science as Culture 18(1), 23-46.

Frank DJ and Gabler J (2006) Reconstructing the university: worldwide shifts in academia in the 20th century. Stanford University Press, Stanford.

Fukuyama F (2004) State building: governance and world order in the 21st century. Cornall University Press, Ithaca, New York.

Geiger RL (2004) Knowledge and money: research universities and the paradox of the marketplace. Stanford University Press, Stanford CA.

Gross ML (1999) The conspiracy theory of ignorance. Harper Collins, New York.

Hacking I (2002) Historical ontology. Harvard University Press, Cambr. Mass.

Karran T (2009) Academic freedom: a research bibliography. http://eprints.lincoln.ac.uk/1763/

Kirp, DL (2003) Shakespeare, Einstein, and the bottom line: the marketing of higher education. Harvard University Press, Cambr., Mass.

Mirowski P (1997) On playing the economics trump card in the philosophy of science: Why it did not work for Michael Polanyi. Philosophy of Science 64 (Issue Supplement), S127-S138.

Nelson C (2010) No university is an island: saving academic freedom. New York University Press, New York \& London.

Nixon J (2011) Higher education and the public good: imagining the university. Continuum, London.

Radder H (ed.) (2010) The commodification of academic research. Science and the modern university. University of Pittsburgh Press, Pittsburgh.

Slaughter S and Rhoades G (2004) Academic capitalism and the new economy. The John Hopkins University Press, Baltimore. 